\title{
Application Study on Active Advanced Support Technology in Deep Roadway under Mine Goaf
}

\author{
Pengfei Jiang, ${ }^{1}$ Peng Xiao, ${ }^{1}$ Fanbao Meng $\left(\mathbb{D},{ }^{1}\right.$ Suolin Jing $\mathbb{D},{ }^{1}$ Jingkai Zhang, ${ }^{2}$ Ge Wang, ${ }^{3}$ \\ and Peng Zhao ${ }^{1}$ \\ ${ }^{1}$ College of Energy and Mining Engineering, Shandong Province (Shandong University of Science and Technology), \\ Qingdao 266590, China \\ ${ }^{2}$ Qingdao Zhengfang Energy Technology Co., Ltd, Qingdao 266520, China \\ ${ }^{3}$ Taian Taishuo Strata Control Technology Co., Ltd, Taian 271000, China
}

Correspondence should be addressed to Fanbao Meng; mfbsdust@163.com and Suolin Jing; 13573246956@163.com

Received 13 August 2020; Revised 5 October 2020; Accepted 24 October 2020; Published 24 November 2020

Academic Editor: Hualei Zhang

Copyright () 2020 Pengfei Jiang et al. This is an open access article distributed under the Creative Commons Attribution License, which permits unrestricted use, distribution, and reproduction in any medium, provided the original work is properly cited.

To solve the problems of the rapid advance of the working face was delayed by complicated working procedure and high labor intensity, and the severe damage of roof bolt (anchor cable) induced by advanced hydraulic support, the deformation characteristics of surrounding rock, and the supporting principle of grouting truss anchor cable were analyzed theoretically by taking the roadway of 3 (down) coal seams 2326\# working face in Sanhekou coal mine as the research object; then, the mechanical model of supporting structure of roadway under goaf was established. Based on this model, the optimal supporting scheme was determined, and the active advanced support technology scheme of "advanced grouting truss anchor cable" was proposed to take the place of the existing single pillar. The deformation and failure characteristics of surrounding rock of the working face leading roadway were observed and analyzed on-site. Within the allowable range of reading error, the results showed that the maximum displacement of medium-deep base point and shallow base point of two roadways was $15.2 \mathrm{~cm}$ and $10.9 \mathrm{~cm}$, respectively; the pressure value had a more obvious jump increase when the distance between each measuring point and the working face was about $35 \mathrm{~m}$, which means the range is strongly affected by the advance mining, and the area affected by advanced mining was $35 \mathrm{~m}$ ahead of the working face. It was observed that the lowest position of roof separation development ranged from $0.71 \mathrm{~m}$ to $2.73 \mathrm{~m}$. The separation layer was generally distributed in the range of $0.73 \mathrm{~m}-2.49 \mathrm{~m}$, and the fracture area was roughly distributed in the range of $0.01 \mathrm{~m}-0.62 \mathrm{~m}$. Under the condition of overlying goaf, there was a complete stress structure, which can meet the requirements of suspension support.

\section{Introduction}

Due to the influence of the advanced abutment pressure and working face mining, the rock surrounding the mining roadway in the working face is easy to deform and destroy and the ground pressure behaviour is relatively strong, which has an adverse impact on the safety and efficient production of the mine [1-4]. At present, in addition to the active support mode in roadway excavation, the passive support mode is mainly the single support with $\Pi$-type steel beam and selfmoving hydraulic support [5-6]. The former support method is simple, but the support strength is low and con- sumes more material [7-10]; the latter has high support strength and fast-moving speed, but it will damage the original support system of the roadway roof [11-15]. Many experts and scholars have done many works to solve the problem in the process of adopting the advanced support. Through theoretical analysis, FLAC $^{3 \mathrm{D}}$ numerical simulation, and field measurement, Chen et al. [16] revealed the distribution law of advance abutment pressure in fully mechanized top-coal caving face. Referring the characteristics of rockburst occurring immediately after the excavation of the tunnel, Bobet et al. [17] and others developed a kind of advanced support technology of actively controlling the 
rockburst based on the analysis of the rockburst process and mechanical mechanism of the tunnel. Wang et al. [18] put forward the critical technology for surrounding rock controlling of the mining roadway with high-stress mudstone roof by analyzing the failure characteristics, mechanical deformation mechanism, and instability reasons for mining roadway with high-stress mudstone roof. Also, some scholars [19-25] used FLAC ${ }^{3 \mathrm{D}}$ to simulate and analyze the pressure of deep surrounding rock and its influence on advanced support, then put forward a new type of comprehensive mechanized driving roadway advanced support.

However, the above research mainly focuses on the passive support mode, and there is less research on the implementation of active support in the mining roadway under the goaf. In this paper, 3_(down) coal seams 2326\# working face mining roadway of Sanhekou coal mine as the research background, based on the roadway roof by the 3_(up) coal seam mining damage, the problem of a large amount of advanced support personnel, using theoretical analysis, field measurement and other means, studies the application of bolt grouting technology instead of advanced support in the advance roadway of working face. The original advanced support system is optimized to further reduce the labor intensity and advance support cost while ensuring the support strength.

\section{The Engineering Situation}

The underground position of 3_(down) coal seams 2326\# working face of Sanhekou coal mine is located in the middle of No. 3 mining area of the mine, with F12 4 branch fault $\left(\angle 70^{\circ}, H=0 \sim 35 \mathrm{~m}\right)$ in the east, bu-5 fault $\left(\angle 70^{\circ}, H=0 \sim 20\right.$ $\mathrm{m})$, three mining tracks and three mining belts in the south, and the intersection of FKT4 fault and f12-4 branch fault in the north. It is the lower coal seam of Shanxi formation 3 of the Permian system. The strike length of the working face is $973 \sim 992 \mathrm{~m}$ (average $982.5 \mathrm{~m}$ ), dip length is $52 \sim 162 \mathrm{~m}$ (average $107 \mathrm{~m}$ ), the area is $87685 \mathrm{~m}^{2}$, coal seam thickness is $3.1 \sim 4.1 \mathrm{~m}$, and the average coal thickness is $3.4 \mathrm{~m}$. The working face is low in the southwest and high in the northeast, and it is a monoclinic structure with an overall dip of $140^{\circ}$ and a coal seam dip angle of $5^{\circ}$ to $7^{\circ}$ whose average value is $6^{\circ}$.

The 3_(down) coal seams 2326\# transport roadway is mainly used for coal transportation and return air of the working face which has a rectangular cross-section, and bolt mesh cable combined support. The net width of the roadway is $4 \mathrm{~m}$, and the net height is $3.2 \sim 4.2 \mathrm{~m}$. The direct roof is siltstone with the thickness of nearly $7.5 \mathrm{~m}$, which is light gray and mainly consists of quartz and feldspar containing a large number of dark minerals; it is well sorted and has fractured, and the rock firmness coefficient (proctor hardness coefficient) $f$ equals to 5.3 . The direct bottom is the mudstone with a thickness of $2.15 \mathrm{~m}$, which is light black and equipped with sandy and argillaceous structure with calcareous, and it is featured by uneven fracture, semihard, and integrity, and the rock firmness coefficient (proctor hardness coefficient) $f$ equals to 4.2. The pressure on the roof and floor of the roadway is massive, and its deformation is severe, mainly

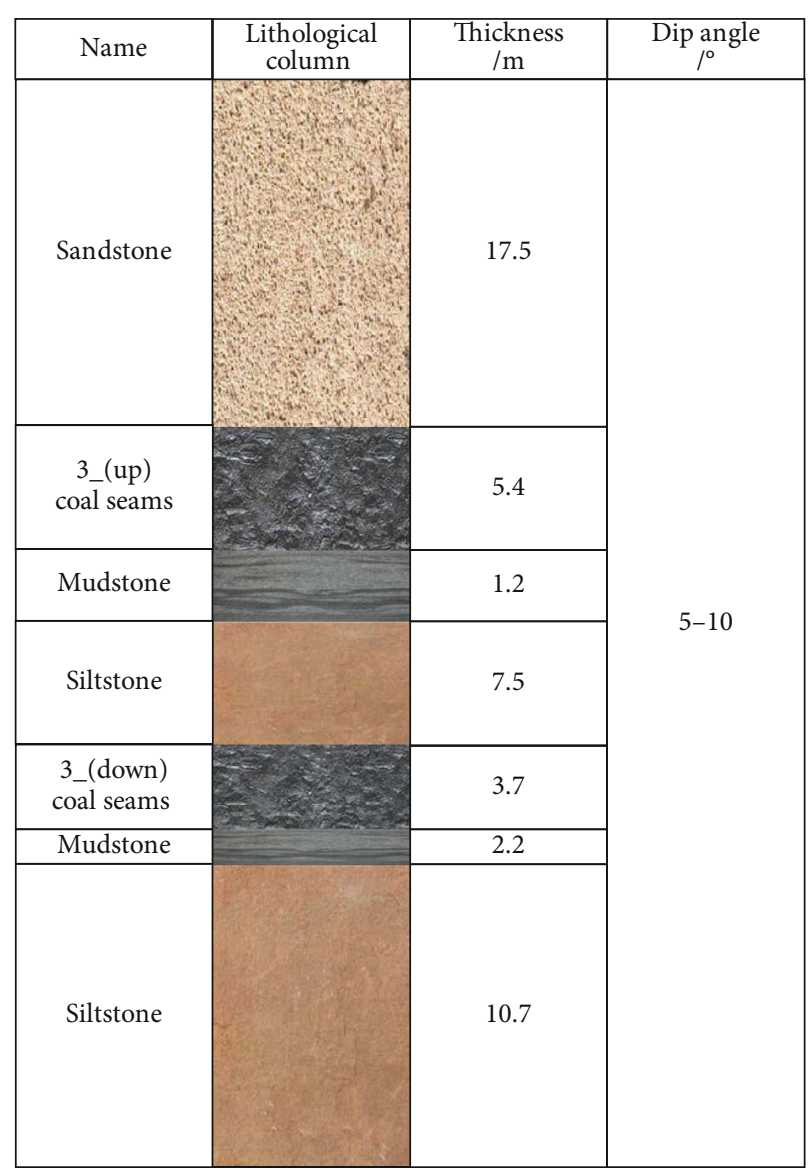

FIgURE 1: Comprehensive histogram of working face.

manifested by floor heave. The roof of the water pouring section sinks, and there is no rockburst phenomenon (see Figure 1 for details).

\section{Failure Law of Surrounding Rock of Roadway under Goaf}

3.1. Pilot Monitoring Program. To study the development characteristics of internal cracks of the rock surrounding the 3_(down) coal seams roadway, learn the stress distribution law of surrounding rock, and determine reasonable advanced grouting support design with high strength and low density, the following monitoring scheme is proposed:

The in situ monitoring is mainly divided into three parts: the bolt (anchor cable) dynameter is used to monitor the stress of roof and sidewall; top plate separator is used to monitor the roof separation of material roadway and transportation roadway; borehole imager is arranged to monitor the development of the loose zone. The overall layout was shown in Figure 2.

The layout scheme of the bolt (anchor cable) dynameter was shown in Figure 3; for the material roadway and transportation roadway, the first group of bolt (anchor cable) dynameter was arranged at $20 \mathrm{~m}$ away from the working face. After that, arrange total of 5 groups with a $20 \mathrm{~m}$ interval. Each group includes 2 bolt (anchor cable) dynameters, which 


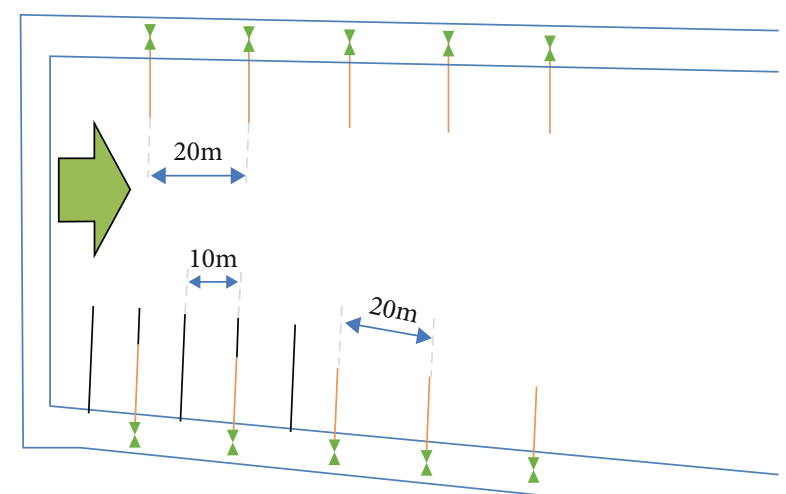

Peephole drilling
Bolt (anchor cable)
dynameter

FIgURE 2: Schematic diagram of measuring point location.

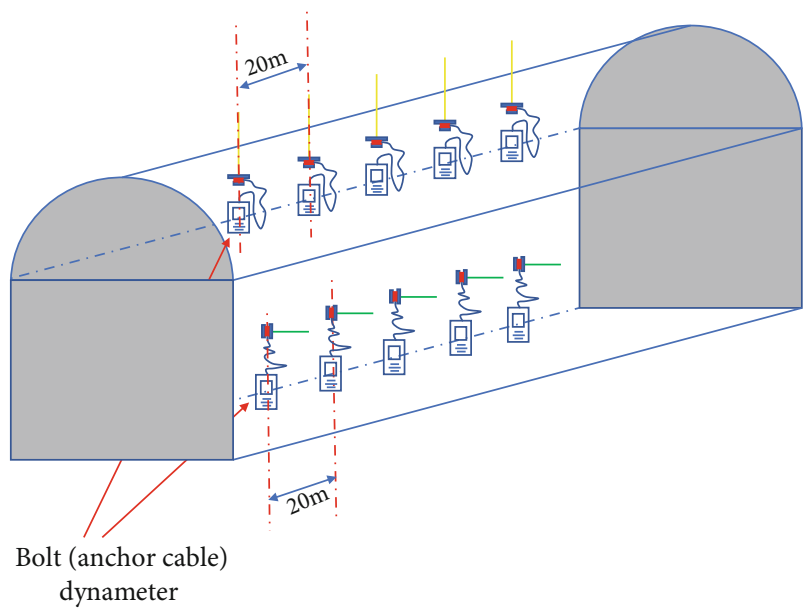

Figure 3: Layout of bolt (anchor cable) dynameter along the roadway.

were, respectively, arranged at the roof and the side of the roadway grade line which close to coal mass.

The layout scheme of the top plate separator was shown in Figure 4; in the material roadway and transportation roadway, the first top plate separator was arranged on the roof at $20 \mathrm{~m}$ away from the working face, with a total of 5 for each roadway.

The layout scheme of the borehole imager was shown in Figure 5; due to the same geological conditions of material roadway and transportation roadway, combining with site construction and equipment placement, it was decided to arrange peeping boreholes in the material roadway for construction and observation. In the material roadway, the first group of peeping hole was arranged at $10 \mathrm{~m}$ away from the working face after stopping coal mining. Then, arrange a total of 5 groups with a $10 \mathrm{~m}$ interval. Each group of peeping boreholes (on the same section) includes two boreholes; they were, respectively, arranged at the roof and the side of the roadway grade which closes to coal mass, and the drilling depth is $5.5 \mathrm{~m}$.

\subsection{Analysis of Monitoring Data}

3.2.1. Analysis of Bolt (Anchor Cable) Dynameter Data. The relationship between the dynameter pressure value and the distance to the working face was shown in Figures 6 and 7 by analyzing the data of anchor cable dynameter pressure: the average peak pressure value of anchor cable dynameter in the material roadway was $123.8 \mathrm{kN}$, and the average pressure increase value was $57.25 \mathrm{kN}$. The changing trend of pressure value measured at each measuring point of the material roadway was roughly same. The average peak pressure of dynameter in the transportation roadway was $177.5 \mathrm{kN}$, and the average pressure increase was $52.5 \mathrm{kN}$. After the preload was applied, the pressure values of the two roadways' dynameter had a significant change within the range of $75 \mathrm{~m}$, which can be considered as the obvious area affected by the advance mining pressure of the working face; according to the pressure data, when the distance between the working face and each measuring point was about $35 \mathrm{~m}$, the pressure value had a more obvious jump-type increase. The roof in this range is strongly affected by the mining.

By analyzing the data of bolt dynameter pressure, the average peak pressure value of sidewall bolt in the material roadway is $30 \mathrm{kN}$, and the average pressure increase value is $11.75 \mathrm{kN}$. The changing trend of pressure value measured at each measuring point of the material roadway was roughly the same. The average peak pressure of sidewall bolt in transport roadway was $36.5 \mathrm{kN}$, and the average pressure increase is $27.5 \mathrm{kN}$. After the preload was applied, the pressure had a significant change within the range of $75 \mathrm{~m}$, which can be considered as the obvious area affected by the advance mining pressure of the working face; according to the pressure data, when the distance between each measuring point and the working face was about $31 \mathrm{~m}$, the pressure value had a more obvious jump-type increase. The surrounding rock in this range was strongly affected by the mining.

Based on the analysis above, the maximum value was chosen and the area with the severe influence of mining was considered as $35 \mathrm{~m}$ ahead of the working face.

3.2.2. Data Analysis of Top Plate Separator. According to the analysis of monitoring data (as shown in Figure 8), the maximum displacement of the deep base point and the shallow base point was $15.2 \mathrm{~cm}$ and $10.9 \mathrm{~cm}$, respectively, within the allowable range of reading error in the transportation roadway. The distance between the $5 \#$ measuring point of transportation roadway and the working face is the farthest, and the time affected by mining was the longest. When it was about $29 \mathrm{~m}$ away from the working face, the monitoring data of the roof separation instrument showed that the displacement increased sharply, which indicated that the roof was seriously affected by the process of mining. It can be considered that the affected scope of transportation roadway by mining was about $29 \mathrm{~m}$ ahead of the working face; the $1 \#$ measuring point of material roadway was $20 \mathrm{~m}$ away from the working face, and the monitoring data increased in the type of step jump. The reason may be that the initial layout was in the area affected strongly by the mining, and there were faults between measuring points $1 \#$ and $2 \#$ and working 


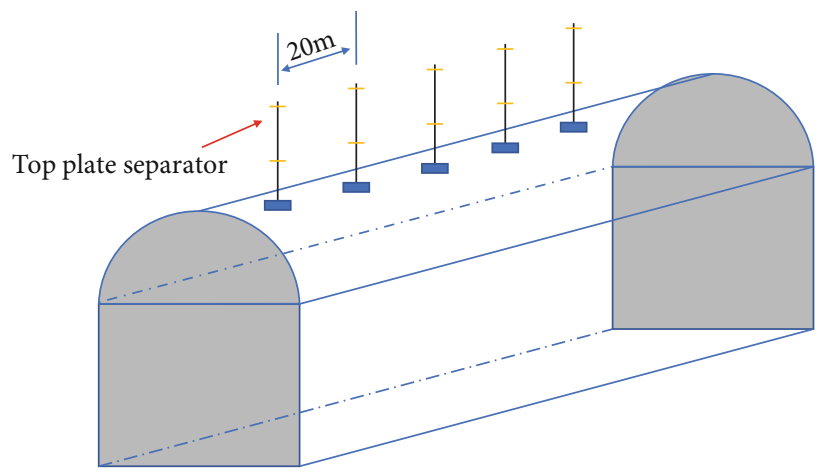

(a) Layout of top plate separator along the roadway

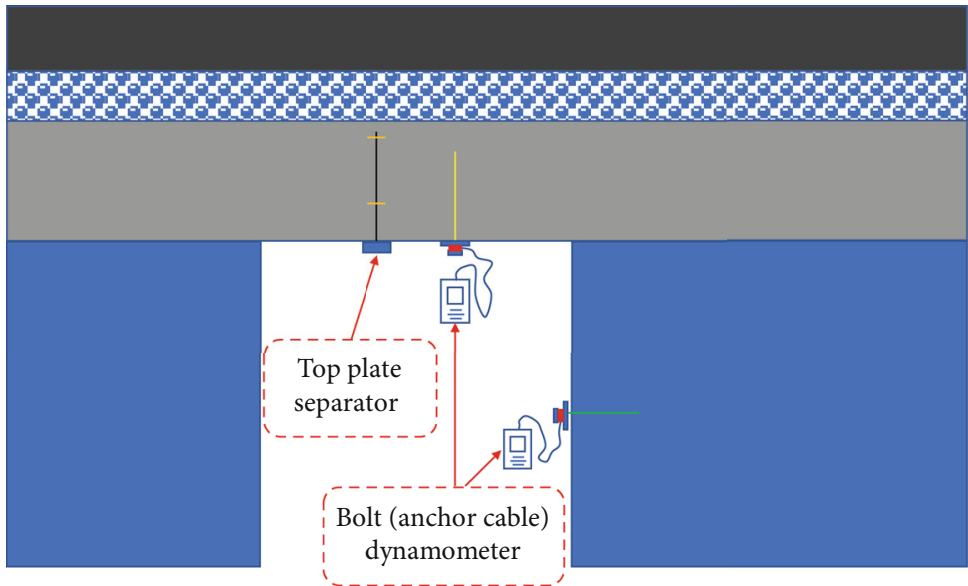

(b) Layout section of top plate separator

Figure 4: Arrangement of measuring points of top plate separator.

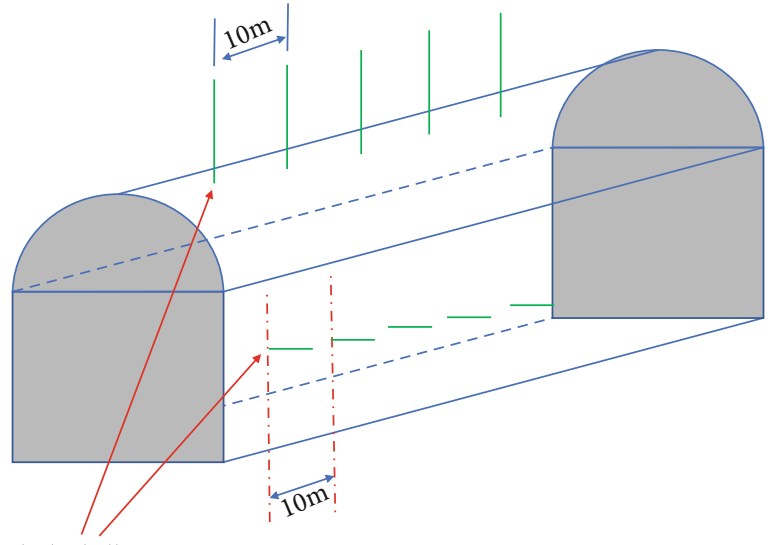

Peephole drilling : $\Phi 32 \mathrm{~mm} \times 5500 \mathrm{~mm}$

(a) Layout of borehole imager along the roadway

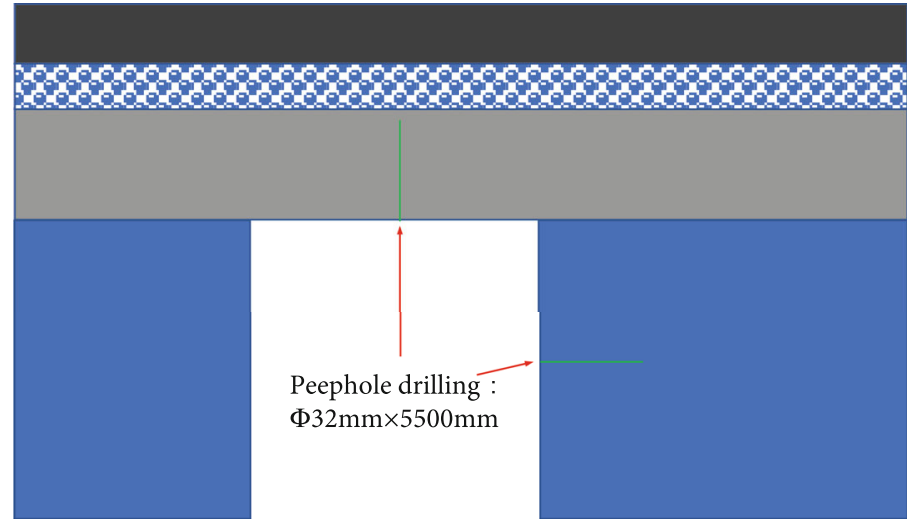

(b) Layout section of borehole imager

Figure 5: Arrangement of borehole observation points.

face. According to the monitoring data of 3\#, 4\#, and 5\# measuring points, the displacement increases by leaps and bounds at the maximum distance of $31 \mathrm{~m}$ away from the working face. It can be considered that the scope of the material roadway affected by mining was about $31 \mathrm{~m}$ ahead of the working face.
3.2.3. Development Characteristics of Surrounding Rock's Loose Zone. The structure and stress state of roadway surrounding rock directly affect the support performance. If we can understand the development characteristics of pore and fracture of the surrounding rock (roof and sidewall) more clearly, it would be of guiding significance for the 


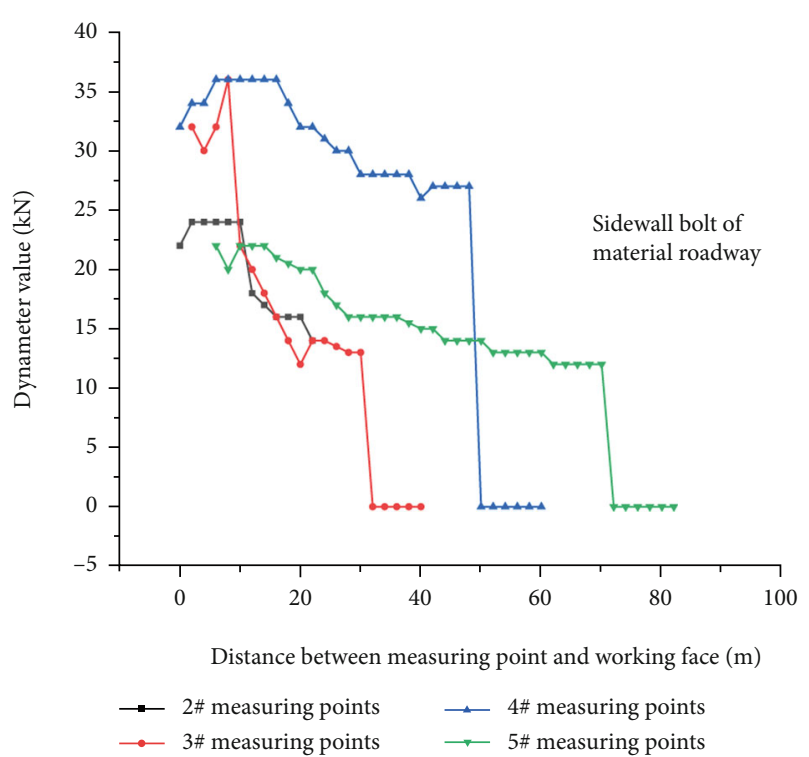

(a)

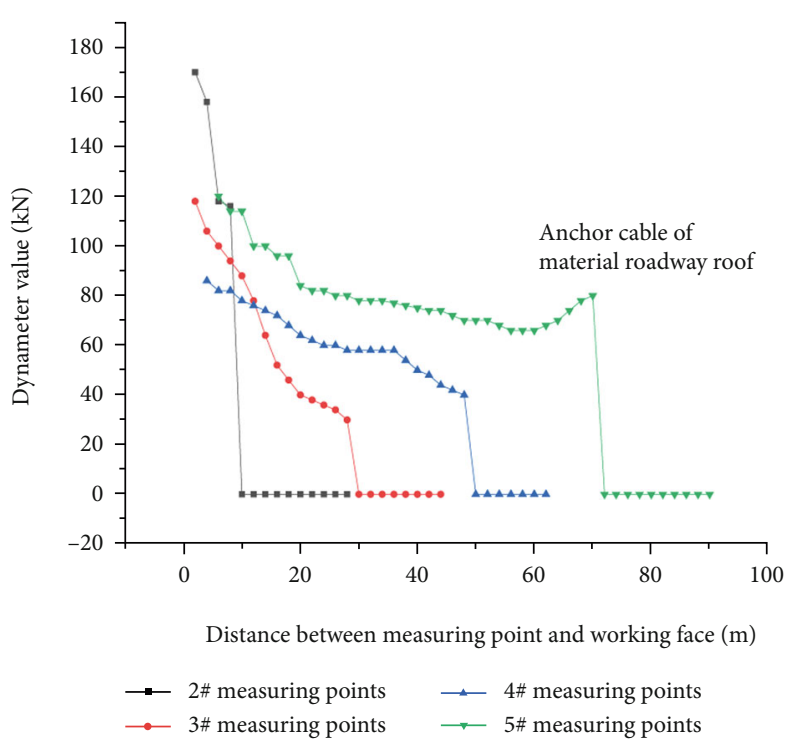

(b)

FIGURE 6: Relationship between pressure value of dynameter in material roadway and distance from working face.

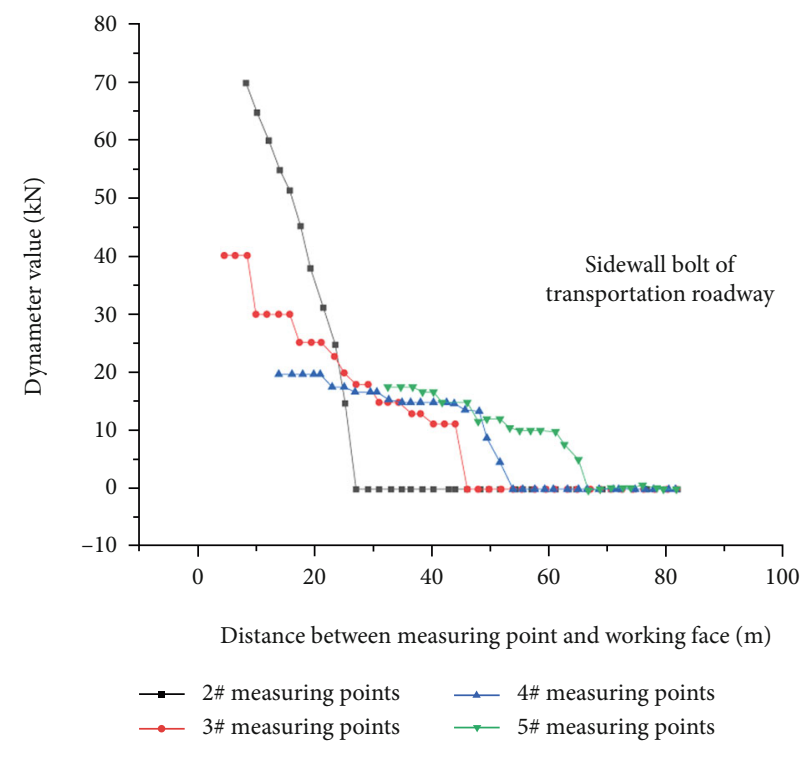

(a)

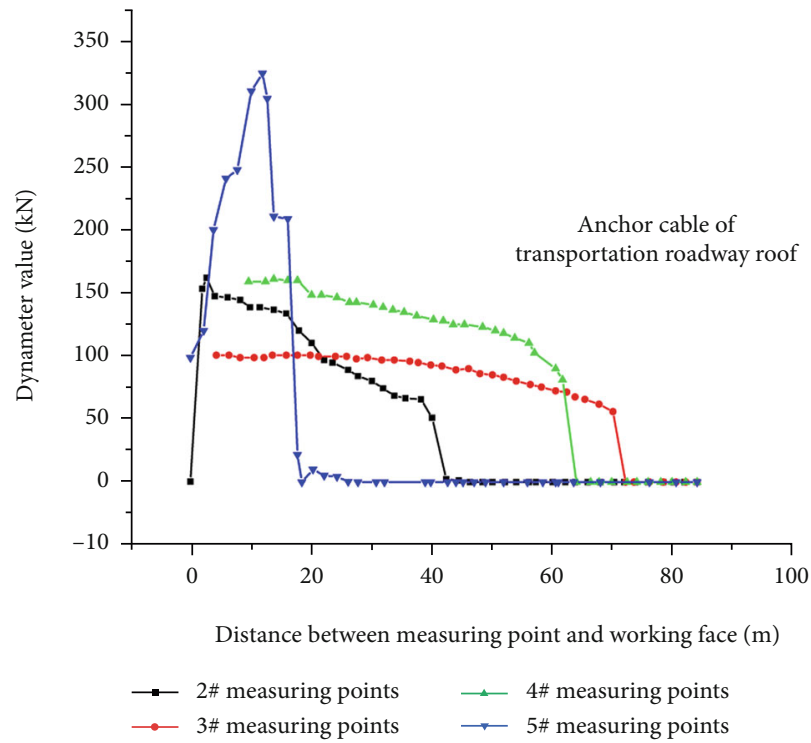

(b)

FIGURE 7: Relationship between the pressure value of dynameter in transportation roadway and the distance from the working face.

selection and evaluation of the support scheme of coal mine field. The instrument used in this experiment is an RBIT-30 borehole imager (as shown in Figure 9) which can observe the distribution of structural and cracks on the roof and sidewall and provide the basis of determining the reasonable length of supporting bolt.

To fully understand the information of borehole, the borehole peep video, borehole expansion map, and histogram were analyzed. This paper summarized and analyzed the development characteristics of rock fractures in each borehole and selected some representative screenshots (as shown in Figure 10) for explanation. According to the characteristics of fracture development and fracture, the roof strata can be divided into crushing zone, absciss layer zone, fissure development zone, and intact zone.

According to the analysis of the observation results (as shown in Table 1), the lowest position of the roof separation layer range is $0.71 \mathrm{~m}$, the highest position is $2.73 \mathrm{~m}$, and the roof separation layer was generally distributed in the roof ranging from $0.73 \mathrm{~m}$ to $2.49 \mathrm{~m}$. The crushing zone was generally distributed in the range of $0.01 \mathrm{~m}$ to $0.62 \mathrm{~m}$. According to the analysis results above, the distribution diagram of the roof separation layer can be drawn (as shown in Figure 11).

3.3. Comparative Analysis of Numerical Simulation. The spatial position of the mining roadway of the 3_(down) coal 


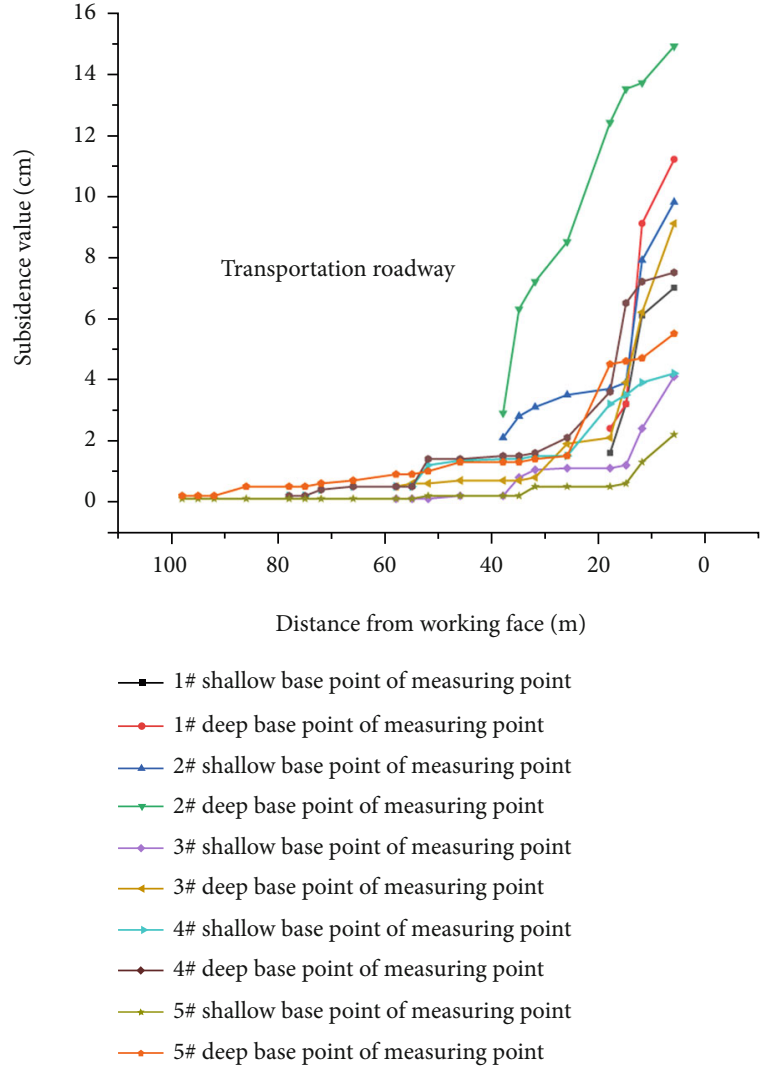

(a)

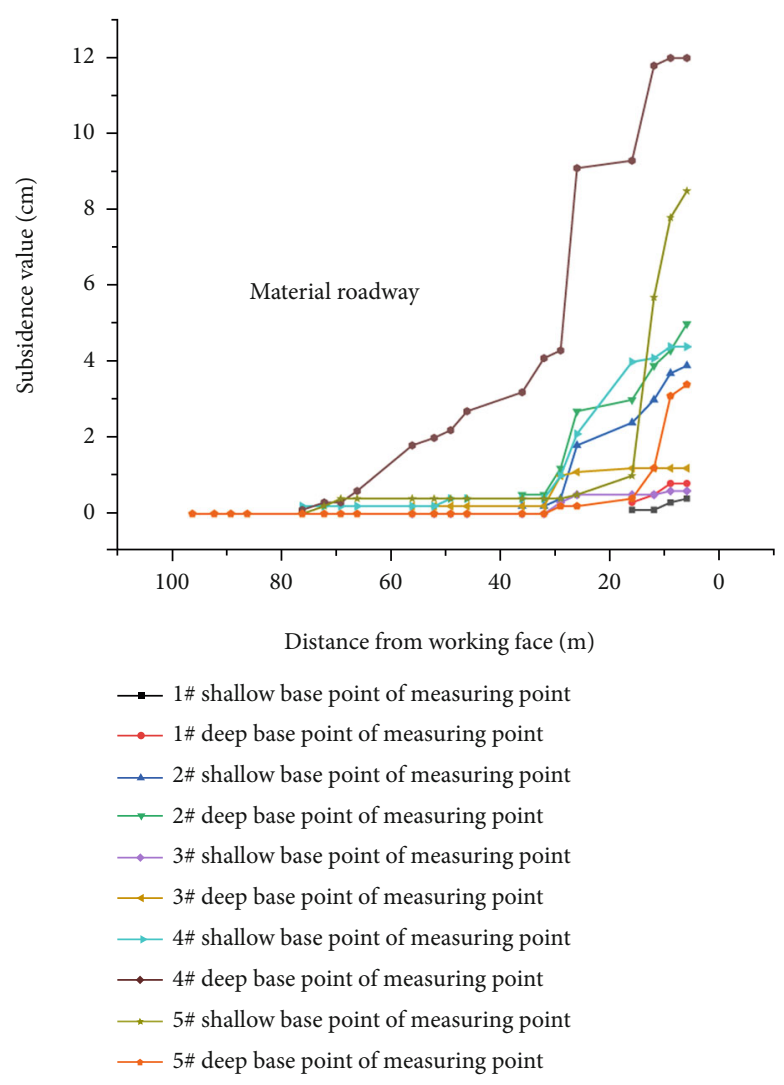

(b)

FiguRE 8: Relationship between the pressure value of dynameter and the distance from the working face.

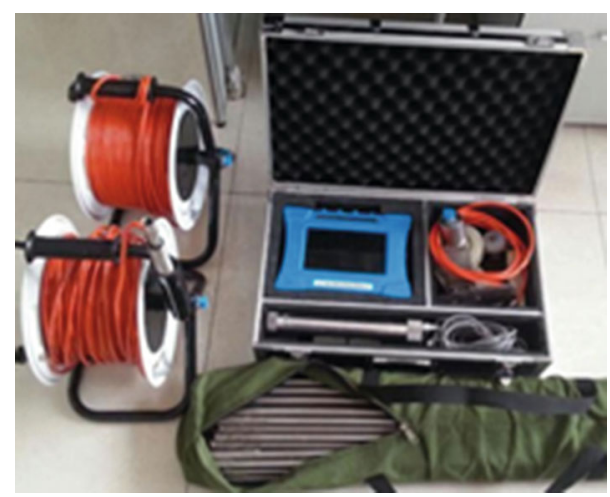

FIGURE 9: RBIT-30 borehole imager.

seams 2326\# working face and goaf of 3_(up) coal seams is staggered. Therefore, the bearing stress of different sections of the mining roadway was different, which leads to the difference between roadway deformation and failure. It is necessary to study and analyze the deformation characteristics of the mining roadway to provide a theoretical basis for optimizing the support schemes.

3.3.1. Establishment of Numerical Simulation Model. The influence range of the stress is about 3 5 times of the roadway width after driving. Based on combining with the actual production of the coal mine, the model size was finally selected as $X \times Y \times Z=160 \mathrm{~m} \times 60 \mathrm{~m} \times 60 \mathrm{~m}$. To reduce the error caused by grid division, the length-width ratio of the grid was limited to be no more than 5. The zones' size far away from the roadway was about $1 \mathrm{~m}$, and the size of the area close to the roadway and the excavation area was $0.5 \mathrm{~m}$. The grid densification was carried out for the critical research area. The model (as shown in Figure 12) consists of 96000 zones and 115356 Gps. A compensation load of $5.91 \mathrm{MPa}$ was applied to the top of the model to simulate the gravity of overlying strata, and $s x x=s y y=10.64 \mathrm{MPa}$. The bottom of the model was restrained to move in vertical direction, and the profile was restrained to move in horizontal direction. The initial displacement in each direction is 0 .

3.3.2. Stress-Strain Field under Goaf. To analyze the deformation and failure of the roadways and provide partition design for roadway support, numerical simulation was carried out on the stress field (as shown in Figure 13) and the distribution of elastic-plastic zone (as shown in Figure 14) around the roadway at different positions under the goaf of working face. The simulation results showed that a pressure-relief zone was formed directly below the goaf after it became stable; the stress concentration was apparent and formed a high-stress area extending downward at the coal side of the mining roadway on both sides. The influence range of both sides was about $30 \mathrm{~m}$ in the horizontal direction of 3_(up) coal seam under the third floor. When the roadway was located in the high-stress area, the bearing load was immense, 

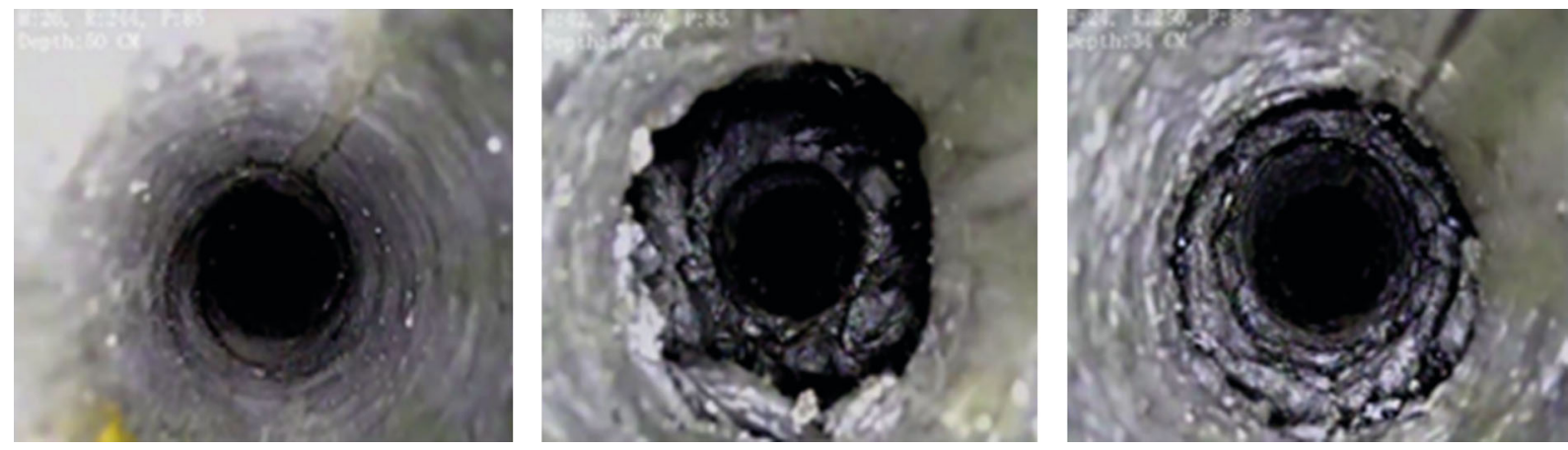

FIgURE 10: Distribution law of cracks in roof strata (3\# drill hole).

TABLE 1: Observation results of RBIT-30 borehole imager.

\begin{tabular}{cccc}
\hline & $\begin{array}{c}\text { Crushing } \\
\text { zone }\end{array}$ & $\begin{array}{c}\text { Absciss layer } \\
\text { zone }\end{array}$ & Fissure development zone \\
\hline $1 \#$ & $0.05 \sim 0.26 \mathrm{~m}$ & $0.95 \sim 1.14 \mathrm{~m}$ & $0.35 \sim 0.48 \mathrm{~m}$ \\
$2 \#$ & $0.01 \sim 0.18 \mathrm{~m}$ & $0.73 \sim 0.85 \mathrm{~m}$ & $0.42 \sim 0.55 \mathrm{~m}$ \\
$3 \#$ & $0.42 \sim 0.62 \mathrm{~m}$ & $1.98 \sim 2.11 \mathrm{~m}$ & $2.34 \sim 2.45 \mathrm{~m}$ \\
$4 \#$ & $0.21 \sim 0.46 \mathrm{~m}$ & $1.75 \sim 1.83 \mathrm{~m}$ & $0.51 \sim 0.65 \mathrm{~m}$ \\
$5 \#$ & $0.12 \sim 0.38 \mathrm{~m}$ & $2.26 \sim 2.49 \mathrm{~m}$ & $0.44 \sim 0.59 \mathrm{~m} \cdot 2.53 \sim 2.78 \mathrm{~m}$ \\
\hline
\end{tabular}

and plastic deformation and failure all happened at the roof and both sides. The stress of the roadway roof was greater than that of the lower side and floor of the roadway. When the roadway was located in the transition range of pressurerelief zone and pressure-rise zone, the elastoplastic deformation of surrounding rock was small. The support strength can be reduced appropriately compared with the roadway in the high-stress area.

By analyzing the field monitoring data, the range of the separation of roadway roof was summarized to determine the reasonable length of anchor cable. At the same time, the scope of the painful area of advance influence of the working face was clarified to determine the reasonable support range. With the help of the numerical simulation software, the plastic failure zone of roadways at different positions under the goaf working face was studied to determine the reasonable support density. In a word, the previous study provided a scientific basis to determine the reasonable scheme of advanced support.

\section{Advance Support Technology of Truss Anchor Cable}

Based on the geological conditions of the Sanhekou coal mine and the pressure characteristics of surrounding rock under the influence of overlying goaf, combining with the roadway surrounding rock support control the regulations in "Coalmine Safe Protocol". The reinforcement and restoration control scheme of Sanhekou coal mine with high prestressed truss anchor cable as the core was established.

4.1. Working Mechanism of Truss Anchor Cable Advanced Support. High prestressed truss anchor support structure (as shown in Figures 15 and 16) is a kind of prestressed sup- port structure that can provide extrusion stress in the horizontal and vertical direction of the roadway roof. It overcomes the defect of single anchor cable support incapable of providing horizontal tension force so that the coal and rock in the anchorage area are in a multidimensional extrusion state. The structure can provide active support force in the horizontal and vertical direction at the same time, and the increase of tensile stress and support force with the roof deformation effectively reduces the maximum tensile stress of coal and rock mass in the middle of the roadway, while the strength and deformation resistance of coal and rock mass are improved. Besides, the steel strand in the structure is in line contact with the roof, the load on the steel strand can be continuously transmitted, and a high pretension can be easily applied. The supporting range is extensive, and the stress state of the loose broken roof is sound. During bending and sinking of the roof, the anchor points of two sides of the truss structure move inward and the stress increases slowly so that the supporting structure is not easy to fail; its locking structure can control the further deformation of the roof and prevent the fateful roof fall accident.

4.2. Advance Support Design. Due to the influence of pillar supporting pressure in goaf, the roof of 3_(down) coal seam 2326\# working face exists zonal failure and deformation. Therefore, the support control process of the surrounding rock of roadway was divided into two stages as follows according to the spatial position relative relationship between the goaf pillar of 3_(up) coal seam and the two roadways in 3_(down) coal seam.

4.2.1. Stage I. When the roadway was located in the distressed zone, the combined support form which consists of the single-unit grouting anchor cable, two $1 \times 7$ strands of high strength and low-relaxation prestressed steel strand with a diameter of $17.8 \times 4000 \mathrm{~mm}$, anchor mesh, and truss anchor cable (without grouting) was adopted to the material and transportation roadways at the distance of $0 \sim 35 \mathrm{~m}$ from the working face. Among them, the single grouting anchor cable was reinforced by a $1 \times 8$-strand middle hole grouting anchor cable in each row, the specification was $\Phi 21.8 \times 6600 \mathrm{~mm}$, and the spacing between rows was $1800 \mathrm{~mm}$; the truss anchor cable adopted two $1 \times 8$ strands of high strength and low-relaxation prestressed steel strand with a diameter of $21.8 \times 6600 \mathrm{~mm}$, 


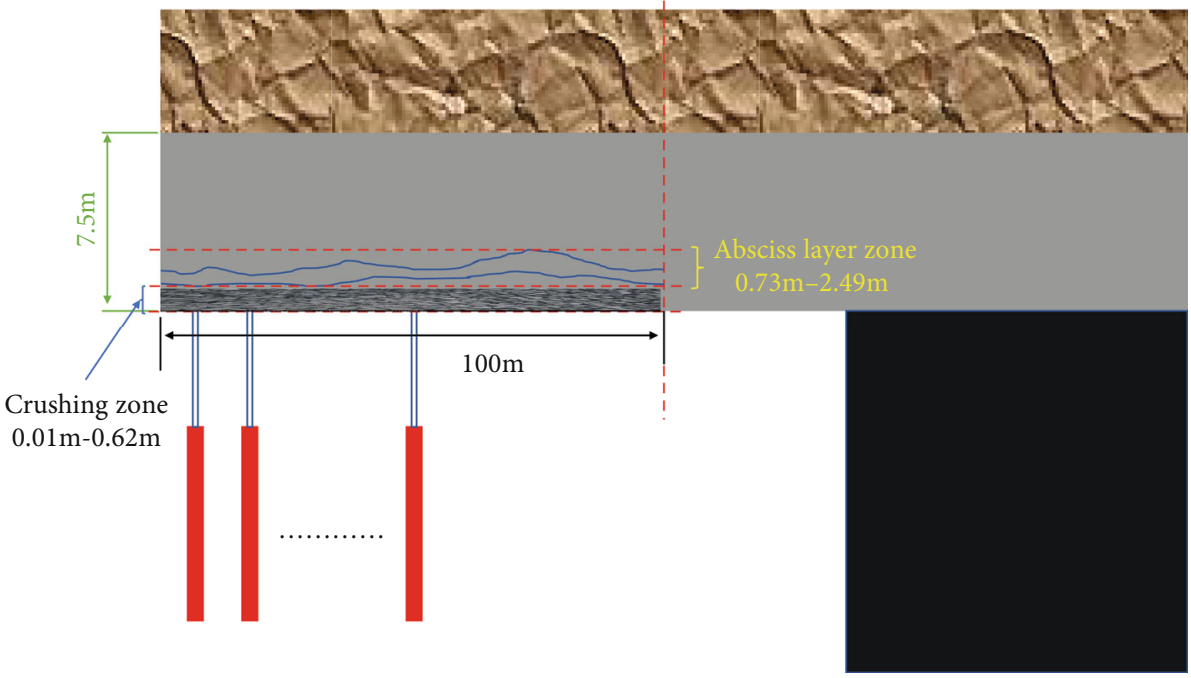

FIGURE 11: Schematic diagram of distribution range of roof separation development area.

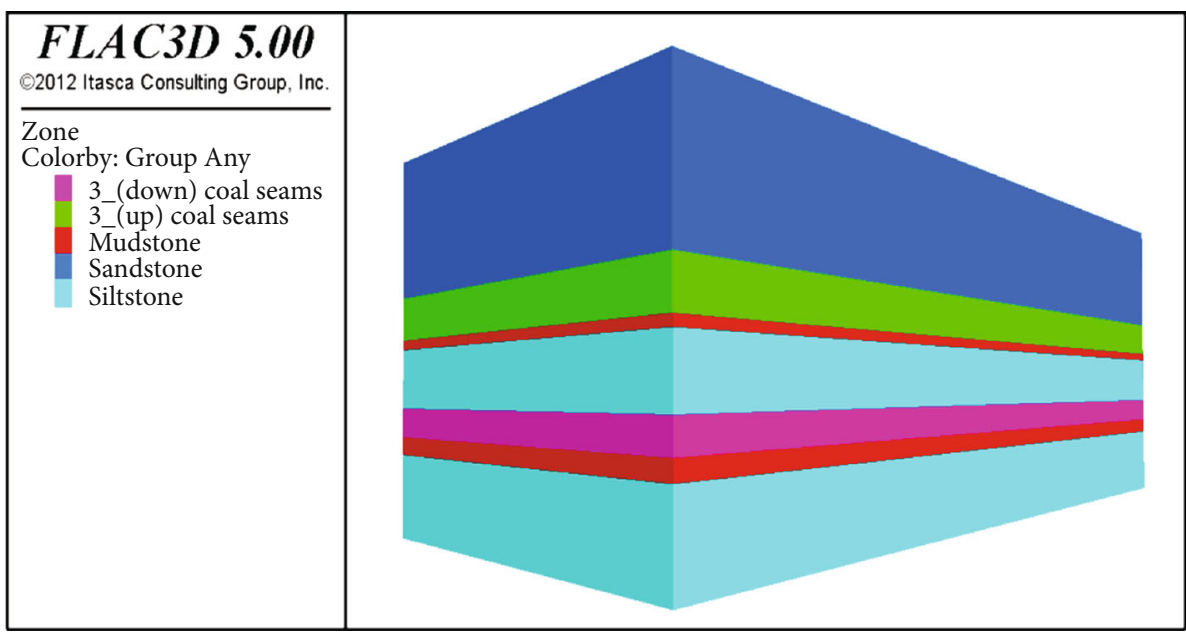

FIGURE 12: Numerical simulation model of mining roadway.

the drilling depth and hole diameter were $6400 \mathrm{~mm}$ and $28 \mathrm{~mm}$, respectively, and the angle between the anchor cable drilling hole and the vertical roof line was $15^{\circ}$. For two $1 \times 7$ strands of high strength and low-relaxation prestressed steel strands, the diameter was $17.8 \times 4000 \mathrm{~mm}$, the spacing was $150 \mathrm{~mm}$, and preload was $25 \mathrm{kN}$. The pretightening force of the anchor cable was $150 \mathrm{kN}$, and the drum tray with the specification of $300 \times 300 \times 16 \mathrm{~mm}$ was adopted. The grouting point was $30-50 \mathrm{~m}$ ahead of the working face. Grouting shall be carried out twice with an interval of 10 to 15 minutes. The first grouting shall be stopped when a large amount of slurry leakage begins. The grouting materials are cement, accelerator, and other mixed materials. During grouting, the pressure was determined to be $2 \mathrm{MPa}$.

4.2.2. Stage II. When the roadway was located in the stress concentration zone, the combined support form which consists of single-unit grouting anchor cable, two $1 \times 7$ strands of high strength and low relaxation prestressed steel strand with a diameter of $17.8 \times 4000 \mathrm{~mm}$, anchor mesh, and grouting truss anchor cable was adopted to the material and transportation roadways at the distance of $0 \sim 35 \mathrm{~m}$ from the working face. Among them, the single grouting anchor cable was reinforced by two $1 \times 8$ strands of medium hole grouting anchor cables with the specification of $\Phi 21.8 \times 6600 \mathrm{~mm}$, and the spacing between rows was set as $1200 \times 1800 \mathrm{~mm}$; the grouting truss anchor cable adopted two $1 \times 8$ strands of high strength and low-relaxation prestressed middle hole grouting anchor cables with the diameter of $21.8 \times 6600$ $\mathrm{mm}$, the drilling depth of $6400 \mathrm{~mm}$, the diameter of $28 \mathrm{~mm}$, and the angle between the anchor cable drilling hole and the roof vertical line was $15^{\circ}$. For two $1 \times 7$ strands of high strength and low relaxation prestressed steel strands, the diameter was $17.8 \times 4000 \mathrm{~mm}$, the spacing was $150 \mathrm{~mm}$, and the preload was $25 \mathrm{kN}$. The pretightening force of the anchor cable was $150 \mathrm{kN}$, and the $300 \times 300 \times 16 \mathrm{~mm}$ high strength drum tray was used (see Figure 17 for details). 


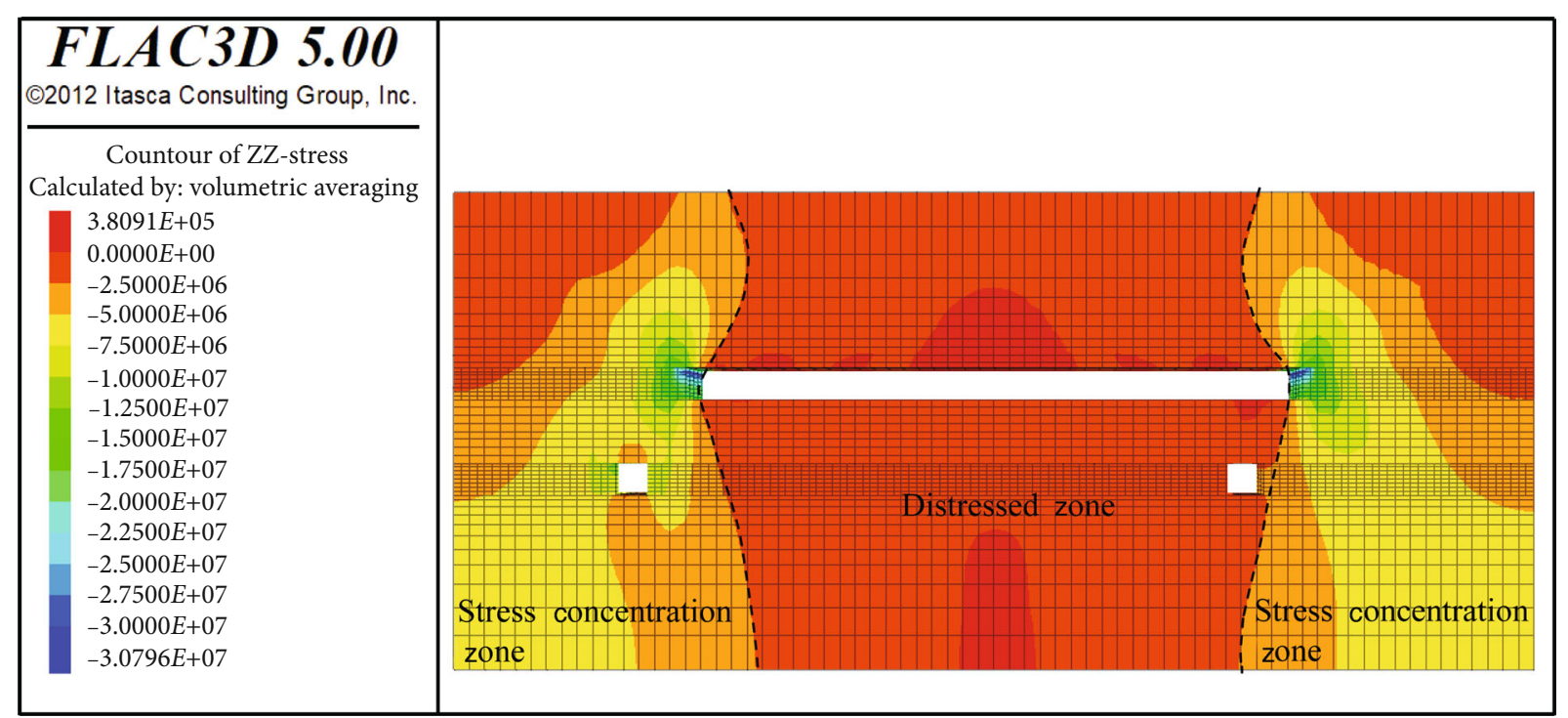

FIgURE 13: The vertical stress field of strata after the above-gob area in stabilization.

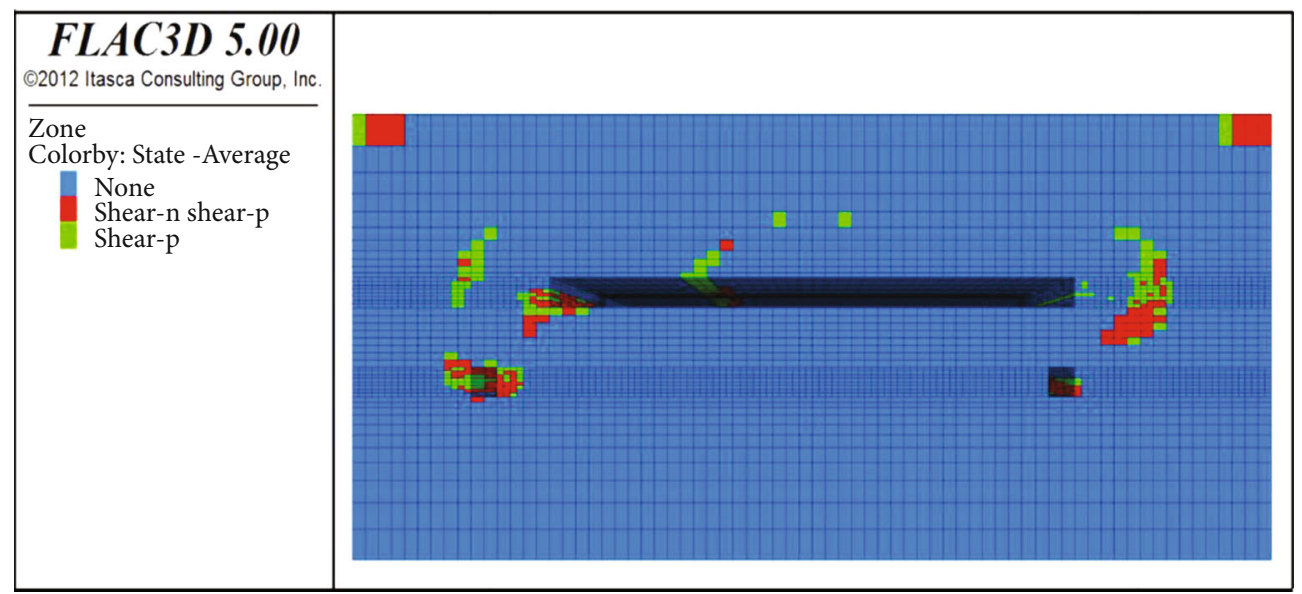

FIGURE 14: Distribution of elastic-plastic zone in surrounding rock of mining roadway.

4.3. Strength Check of Advanced Support. According to the original advanced support scheme of 3_(down) coal seam 2326\# working face in Sanhekou coal mine, the minimum support resistance per unit area and the maximum support resistance were $150 \mathrm{kN}$ and $195 \mathrm{kN}$, respectively.

According to the advanced support scheme of working face at stage I, the mechanical model of the support structure was constructed (as shown in Figure 18), and the support resistance per unit area was obtained as follows:

$$
P=\frac{k F(1+2 \cos \theta)}{a \times b},
$$

where $p$-support resistance per unit area, $\mathrm{kN} / \mathrm{m}^{2}$; $F$-broken load of grouting anchor cable, $530 \mathrm{kN}$; $k$-safety factor, taken as $0.8 ; a$-roadway width, $\mathrm{m} ; b$-spacing between anchor cables of truss, $\mathrm{m}$; $\theta$-the angle between truss anchor cable and vertical roof line, taken as $30^{\circ}$.
The support resistance per unit area was $160.89 \mathrm{kN} / \mathrm{m}^{2}$, which was more than $150 \mathrm{kN} / \mathrm{m}^{2}$ and met the support requirements.

According to the advanced support scheme at stage II, the mechanical model of the support structure was constructed (as shown in Figure 19), and the support resistance per unit area was obtained as follows:

$$
P=\frac{2 k F(1+\cos \theta)}{a \times b},
$$

where $p$-support resistance per unit area, $\mathrm{kN} / \mathrm{m}^{2}$; $F$-broken load of grouting anchor cable, $530 \mathrm{kN} ; k$-safety factor, taking 0.8 ; $a$-working face width, $\mathrm{m} ; b$-spacing between anchor cables of truss, $\mathrm{m} ; \theta$-the angle between truss anchor cable and vertical roof line, $30^{\circ}$.

The support resistance per unit area was $219.78 \mathrm{kN} / \mathrm{m}^{2}$, which was more than $195 \mathrm{kN} / \mathrm{m}^{2}$ and met the support requirements. 


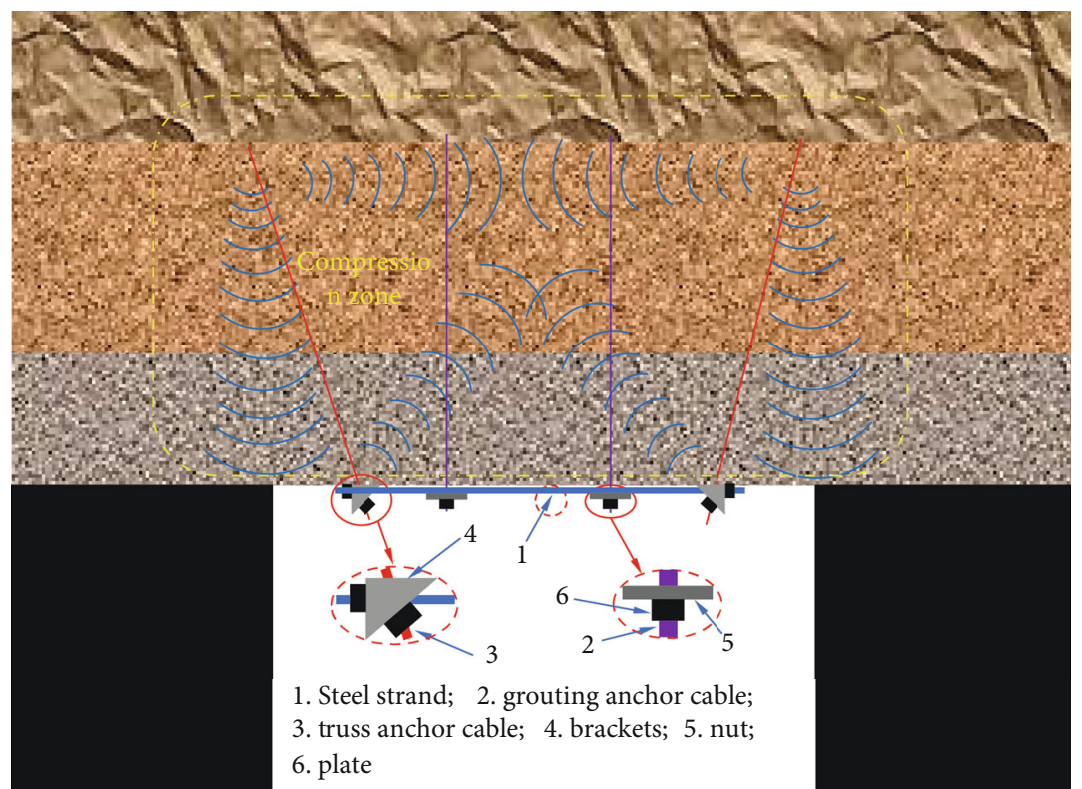

FIgURE 15: Schematic diagram of truss anchor cable support structure.

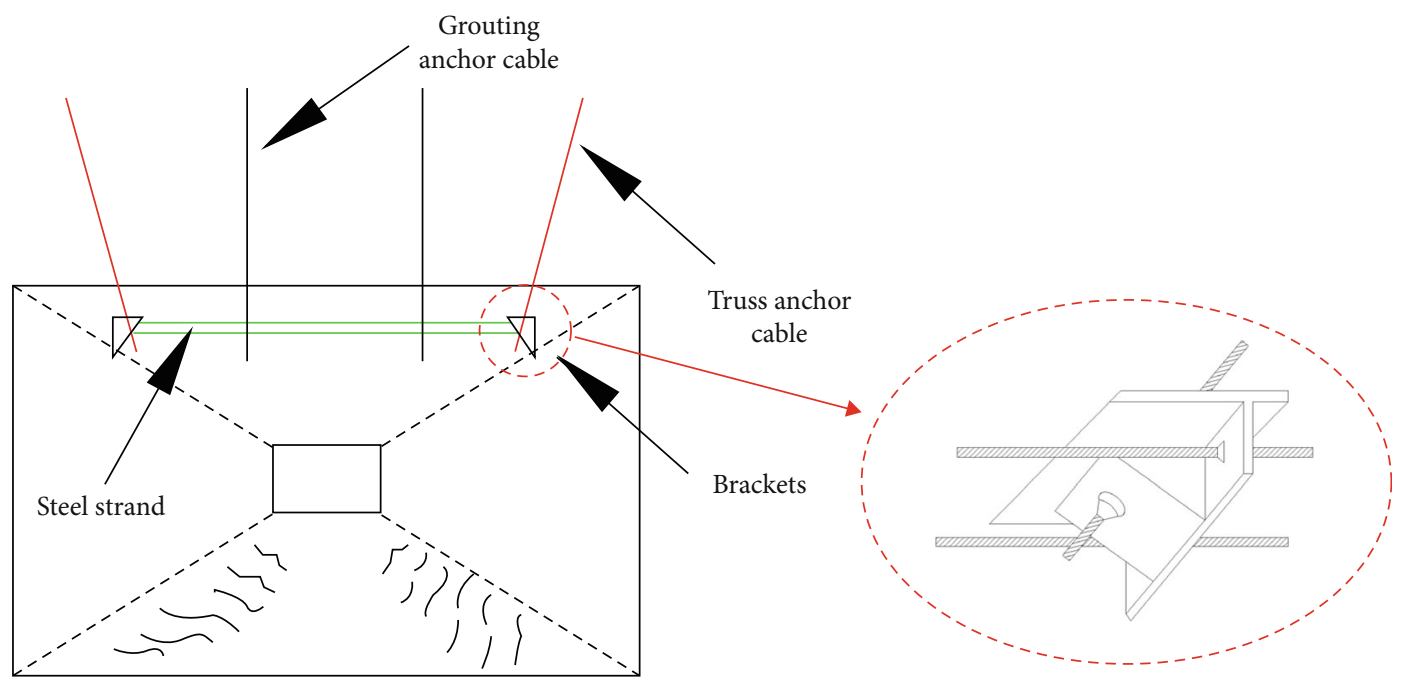

FIGURE 16: Schematic diagram of high-strength pretightening steel strand bracket.

\section{Conclusion}

(1) After analyzing the supporting principle of prestressed truss grouting anchor cable, it can be indicated that the structure overcomes the defect of the single anchor cable support incapable of providing the horizontal tension force so that the coal and rock mass in the anchorage zone were always in a multidimensional compression state. This structure can provide active support force in the horizontal and vertical direction at the same time, and the tensile stress and support force increased with the roof deforming, which effectively reduced the maximum tensile stress of coal and rock mass in the middle of the roadway and improved the strength and deformation resistance of coal and rock mass. Besides, the steel strand in the structure was in line contact with the roof, the load on the steel strand can be continuously transmitted, and a high pretension can be easily applied. The supporting range is extensive, and the stress state of the loose broken roof is sound

(2) By observing and analyzing the deformation and failure characteristics of advanced roadway in working face, it can be concluded within the allowable range of reading error; the maximum displacement of medium-deep base point and shallow base point of two roadways was $15.2 \mathrm{~cm}$ and $10.9 \mathrm{~cm}$, respectively; the pressure value has a more obvious jump-type increase when the distance between each measuring point and the working face was about $35 \mathrm{~m}$, which means the range was strongly affected by the advance 


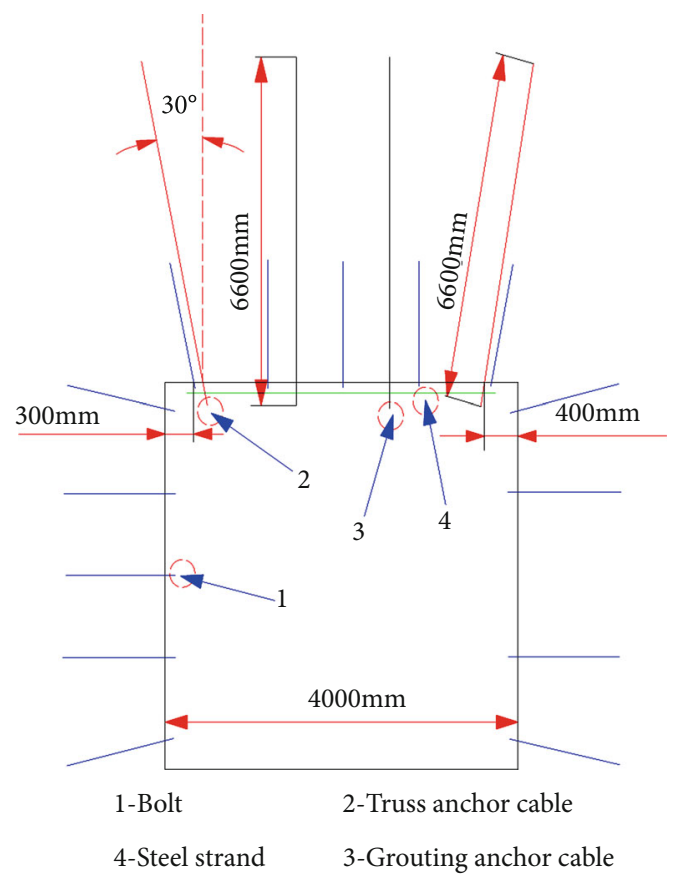

(a) Section diagram of advanced support

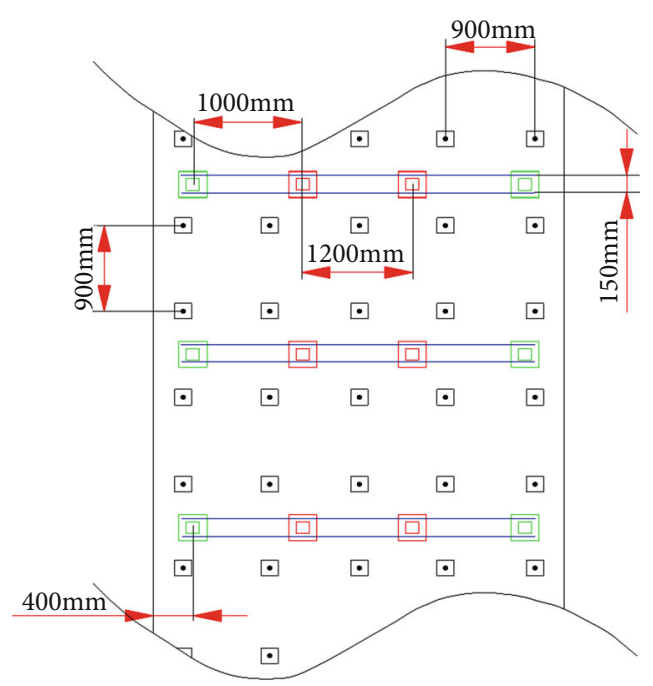

G Grouting anchor cable $\square$ Truss anchor cable $๑$ Bolt — Steel strand

(b) Unfolding drawing of advanced support

Figure 17: Schematic diagram of advanced support scheme design.

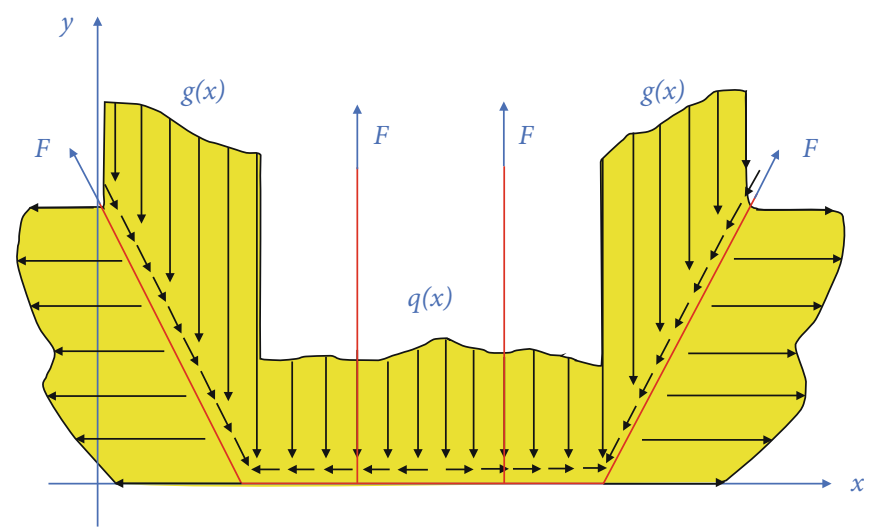

FIgURE 18: Mechanical model of support structure in stage I.

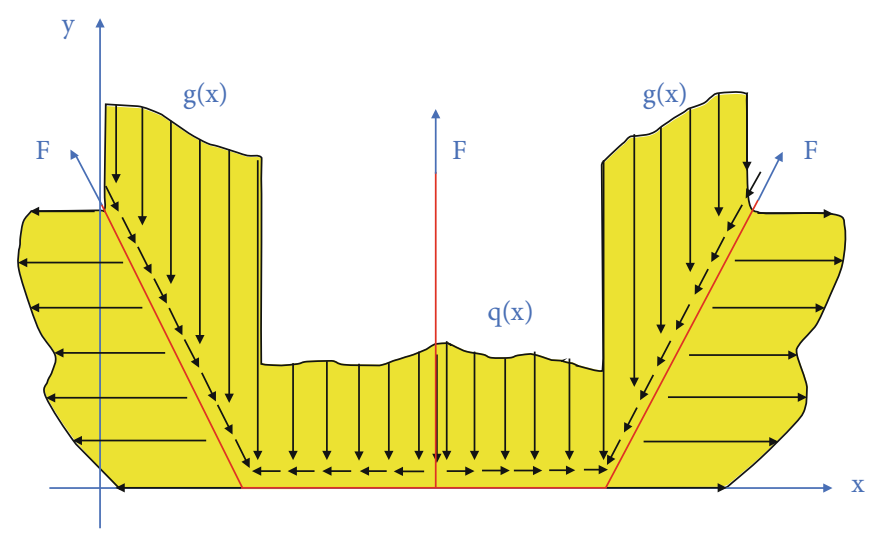

FIgURE 19: Mechanical model of support structure in stage II. 
mining, and the area affected by the advance mining was $35 \mathrm{~m}$ ahead of the working face; the lowest position of roof separation was $0.71 \mathrm{~m}$, and the highest was $2.73 \mathrm{~m}$. The overall distribution of roof separation ranged from $0.73 \mathrm{~m}$ to $2.49 \mathrm{~m}$. The fracture zone was generally distributed in the range of $0.01 \mathrm{~m}$ $0.62 \mathrm{~m}$

(3) After grouting with grouting anchor cable, the joints and fissures in the roof were filled with slurry, which increased the integrity and bearing capacity of the roof. At the same time, the advanced monomer hydraulic prop was cancelled so that the mining time and the labor intensity were reduced and the coal mine production efficiency was improved

\section{Data Availability}

The data used to support the findings of this study are available from the corresponding author upon request.

\section{Conflicts of Interest}

The authors declare no conflicts of interest.

\section{Acknowledgments}

This study was supported by Shandong Provincial Natural Science Foundation of China (ZR2018MEE001), the National Natural Science Foundation of China (No. 51974174), Qingdao source innovation plan (18-2-2-68-jch), and the Scientific research projects of colleges and universities in Shandong Province (J18K2010), and Shandong Province's Taishan Scholar Talent Team Support Plan for Advantaged \& Unique Discipline Areas. The authors are grateful to the reviewer for his/her valuable comments and suggestions.

\section{References}

[1] G. S. P. Singh and U. K. Singh, "Influence of strata characteristics on face support requirement for roof control in longwall workings - a case study," Mining Technology, vol. 121, no. 1, pp. 11-19, 2012.

[2] Z. Wen, X. Wang, Q. Li, G. Lin, S. Chen, and Y. Jiang, "Simulation analysis on the strength and acoustic emission characteristics of jointed rock mass," Tehnicki Vjesnik - Technical Gazette, vol. 23, no. 5, 2016.

[3] K. Hongpu, "Stress distribution characteristics and strata control technology for roadways in deep coal mines," Coal Science and Technology, vol. 41, no. 9, pp. 12-17, 2013.

[4] Z. Yingda, "The mechanics effect of bolt pretension in roadway surrounding rock," Journal of China Coal Society, vol. 33, no. 8, pp. 856-859, 2008.

[5] R. Cao, P. Cao, and H. Lin, "Support technology of deep roadway under high stress and its application," International Journal of Mining Science and Technology, vol. 26, no. 5, pp. 787793, 2016.

[6] H. Xie, F. Gao, and Y. Ju, "Research and development of rock mechanics in deep ground engineering," Chinese Journal of Rock Mechanics \& Engineering, vol. 34, no. 11, pp. 21612178, 2015.
[7] R. Peng, X. Meng, G. Zhao, Y. Li, and J. Zhu, "Correction: experimental research on the structural instability mechanism and the effect of multi-echelon support of deep roadways in a kilometre-deep well," PLoS ONE, vol. 13, no. 9, article e0204059, 2018.

[8] Y. Kang, Q. Liu, G. Gong, and H. Wang, "Application of a combined support system to the weak floor reinforcement in deep underground coal mine," International Journal of Rock Mechanics and Mining Sciences, vol. 71, pp. 143-150, 2014.

[9] M. Jawed and R. K. Sinha, "Design of rhombus coal pillars and support for roadway stability and mechanizing loading of face coal using SDLs in a steeply inclined thin coal seam-a technical feasibility study," Arabian Journal of Geosciences, vol. 11, no. 15, 2018.

[10] M. R. Zareifard and A. Fahimifar, "Analytical solutions for the stresses and deformations of deep tunnels in an elastic-brittleplastic rock mass considering the damaged zone," Tunnelling and Underground Space Technology, vol. 58, pp. 186-196, 2016.

[11] Z. Wen, Y. Jiang, Z. Han, S. Yang, and X. Wang, "Anchoring principles of a new energy-absorbing expandable rock bolt," Engineering Transactions, vol. 64, no. 1, pp. 89-103, 2016.

[12] H. He, L. M. Dou, S. Y. Gong, L. L. Wang, and X. F. Zhang, "Mechanism of rockburst prevention and supporting control technology in roadways," Journal of Mining \& Safety Engineering, vol. 27, no. 1, pp. 40-44, 2010.

[13] A. Bobet and H. Yu, "Full stress and displacement fields for steel-lined deep pressure tunnels in transversely anisotropic rock," Tunnelling and Underground Space Technology, vol. 56, pp. 125-135, 2016.

[14] Z. Wen, Y. Shi, Z. Cui, and R. Wang, "Study of stress features of fully grouted prestressed anchors," Rock \& Soil Mechanics, vol. 31, pp. 177-181, 2010.

[15] W. R. Liu, "Experimental and numerical study of rock stratum movement characteristics in longwall mining," Shock and Vibration, vol. 2019, Article ID 5041536, 15 pages, 2019.

[16] C. Qiao, C. H. Li, X. M. Wei, and Y. Y. Hu, "Numerical simulation study on the evolution law of mine pressure in deep mining," Arabian Journal of Geosciences, vol. 13, no. 12, 2020.

[17] A. Bobet and H. H. Einstein, "Tunnel reinforcement with rockbolts," Tunnelling and Underground Space Technology, vol. 26, no. 1, pp. 100-123, 2011.

[18] W. Guofa and N. Yanqi, "Study on advance hydraulic powered support and surrounding rock coupling support system and suitability," Coal Science \& Technology, vol. 24, no. 9, pp. 1925, 2016.

[19] Z. Guofeng, Z. Kaihua, Z. Chun, and J. Long, "Failure mechanism and support design of interclated roadway surrounding inclined coal seam in Qishan Coal Mine," Journal of Mining \& Safety Engineering, vol. 28, no. 1, pp. 22-27, 2011.

[20] P. Jing and W. Wencai, Study on digital simulation of mine roadway advance support based on flac-3d, World Nonferrous Metals, 2017.

[21] X. Guanghui, G. Jian, C. Jijie et al., "Design of advance support for deep fully-mechanized heading roadway and its support performance analysis," Coal Science and Technology, vol. 46, no. 12, pp. 15-20, 2018.

[22] Z. Yangfa, J. U. Wenjun, K. Hongpu, W. Zhanling, and J. Pengfei, "Combined test research on coal pillar width setting of district sublevel for fully-mechanized face with large mining height based on 3d dynamic strain monitoring," Journal of Mining \& Safety Engineering, vol. 31, no. 3, pp. 359-365, 2014. 
[23] H. Zhang, X. Miao, G. Zhang, Y. Wu, and Y. Chen, "Nondestructive testing and pre-warning analysis on the quality of bolt support in deep roadways of mining districts," International Journal of Mining Science and Technology, vol. 27, no. 6, pp. 989-998, 2017.

[24] Y. Xin and L. Mu, "Analysis of instability characteristics of surrounding rocks in mudstone roof gateway subjected to high stress and its control," Journal of Mining \& Safety Engineering, vol. 34, no. 3, pp. 519-526, 2017.

[25] G. Li, F. Ma, J. Guo, H. Zhao, and G. Liu, "Study on deformation failure mechanism and support technology of deep soft rock roadway," Engineering Geology, vol. 264, article 105262, 2020. 